\title{
Planeten-Beobachtungen am Meridian-Kreise der Altonaer Sternwarte, von Herrn Observator Pape.
}

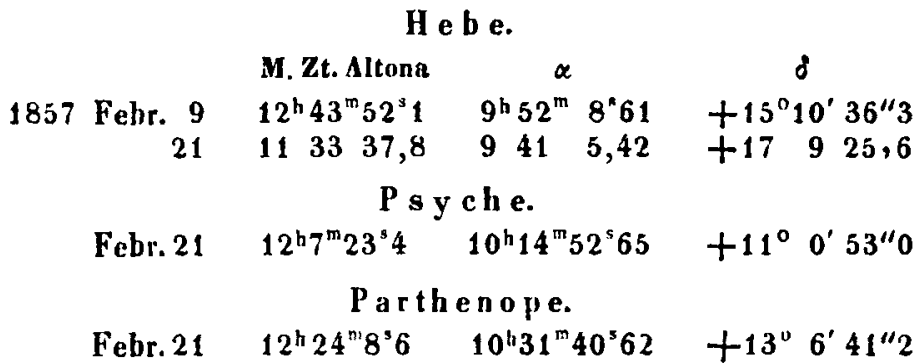

In den Monaten Februar und März 1857 konnten die Beobachtüngen 'am Meridian-Kreise wegen vorgenommener Bauten am Sternwartsgebäude weniger regelmässig und eine lange Zeit hindurch gar nicht ausgeführt werden. Es ist dies der Grund, weshalb von den hier übernommenen Planeten nur eine so geringe Anzahl von Beobachtungen gegeben werden kann.

Altona 1857 Juli 2.

Einige Notizen über das kleine Observatorium des Herrn Dr. Habicht in Gotha. Aus einem Schreiben des Herrn Dr. Habicht an den Herausgeber.

Das Observatorium hesteht aus drei kleinen Riumen, von denen aus die Pendel-Uhr gesehen und gehört werden kann. Die Uhr ist von der besten Art aus Utzschneider und Fraunhofer's Anstalt, das Mahler'sche Pendel aber gegen ein Tiede'sches Quecksilberpendel vertauscht. Ihr Gang ist sehr gut und wird streng controllirt.

In ersten Raume ist das 22zöllige Passageninstrument und im Meridiane vor demselben steht das Repsold sche Universalinstrument.

Im zweiten Raume ist der Durchschnift vou Ost nach West, und sind daselbst die Zapfenlager, Gegengewichte etc. so aufgestellt, dass ich die Axe dez Passageninstruments aus dem ersten Raume unmittelhar dahin einlegen kann, und so dieses Instrument in heiden Richtungen benutzt ist. Auch hier ist durch einen isolirten Pfeiler im 1 sten Verticale dafür gesorgt, dass das Universalinstrument da aufgestellt werden kann, und dieses also als Mire benutzt, oder auch zu ZeitBeobachtungen in Meridian, oder zu Polhühen-Beobachtungen im 1sten Verticale dient. Die Reihe aller dieser sich controllirenden Beobachtungen ist geschlossen und hat sich eine sehr erfreuliche Uebereinstimmung herausgestellt.
Sobald ich mit der Längenbestimmung im Reinen bin, werde ich die Ehre haben, Ihnen über dies Alles einen Bericht $2 u$ geben.

Das Resultat ist Polhöhe $=50^{\circ} 57^{\prime} 11^{\prime \prime} 5$.

Länge (noch unsicher) aus topogr. Hülfsmitteln durch Reduction auf den Seeberg und Hansen's Privatsternwarte

Sternw. Habicht-Greenwich $42^{\prime} 52^{\prime \prime} 13$ öst. in Zeit

Sternw. Habicht-Berlin $10^{\prime} 45^{\prime \prime} 27$ westl.

Im dritten Raume mit Drehkuppel ist der Fraunhofer'sche Refractor von 42 Linien Oeffnung mit Belcuchtungsvorrichtung des Feldes oder der Fäden allein. Das Filarmikrometer hat 5 Stundenfäden und 3 vereint bewegliche über drei unbeweglichen Fäden in Declination. Ausserdem die gewöhnlichen Kreismikrometer etc.

Barometer, Thermonteter etc. sind natürlich mit Vorsicht aufgestellt. Ein magnetischer Apparat harrt noch eines passenden Locals. Mein Chronometer ist ein Kessel scher (고 1275).

W. Habicht.

\section{Schreiben des Herrn Dr. Förster an den Herausgeber.}

Reifolgend erlaube ich nir, Ihnen eine rohe und eine genaue Position des Plaueten 45 zu schicken, die vielleicht zur Interpolation einstweilen dienen könned. Ich erhielt an 30. Juni unter einer grösseren Zahl von beiläufigen Sternpositionen auch diese, die dem Planeten entsprach:

$$
\text { Juni } 30 \quad 13^{\mathrm{b}} 30^{\mathrm{m}} \quad 16^{\mathrm{h}} 22^{\mathrm{m}} 44^{\mathrm{s}} \quad-11^{\circ} 47^{\prime} 5
$$

Dagegen Juli 2 folgenden genauen Ort:

$$
\text { Juli } 2 \quad 11^{\mathrm{h}} 36^{\mathrm{m}} 26^{\mathrm{s}} \quad 245^{\circ} 27^{\prime} 26^{\prime \prime} 5 \text {. }-11^{\circ} 52^{\prime} 31^{\mu} 7
$$

Berlin 1857 Juli 6 .

W. Förster. 